\title{
Design And Analysis Of Water Supply And Drainage Engineering For A Residential Building
}

\author{
Suxian $\mathrm{Ye}^{1,2, *}$, Jingwen $\mathrm{Li}^{1,2}, \mathrm{Jiao}$ Yuan ${ }^{1,2}, \mathrm{Yao} \mathrm{Hu}^{1,2}$, Xiaoqiang $\mathrm{Han}^{1,2}$ \\ ${ }^{1}$ Guilin University of Technology, Guilin, Guangxi, China \\ ${ }^{2}$ Guangxi Key Laboratory of Spatial Information and Geomatics, Guilin, Guangxi, China
}

\begin{abstract}
Nowadays, the demand for architecture by the public is not only a living, but also an increase in comfort and safety requirements, and more attention is paid to the design of water supply and drainage works for buildings.In recent years, the rapid development of the economy, whether it is urban or township, the degree of housing community is getting higher and higher, people's requirements for the water supply and drainage function of the building are also constantly improving, which gives the water supply and drainage project a broader development space.In this paper, the nine-story building in a certain district is taken as the research object, and the design analysis is carried out according to the relevant data of the building and the living needs of the residents to verify the feasibility.According to the four parts of water supply, drainage, fire protection and rainwater drainage, the water supply and drainage project of the building is analyzed, and the construction points are briefly given.It can effectively improve the design level and quality of the water supply and drainage system of the building, and facilitate the use of domestic water for residents.
\end{abstract}

\section{Introduction}

In recent years, the rapid development of the economy, whether it is urban or township, the degree of housing community is getting higher and higher, people's requirements for the water supply and drainage function of the building are also constantly improving, which gives the water supply and drainage project a broader development space.In this paper, the nine-story building in a certain district is taken as the research object, and the design analysis is carried out according to the relevant data of the building and the living needs of the residents to verify the feasibility[1].

\section{Building water supply design}

The nature of the building's use, the water pressure of the municipal pipe network, and the total height of the building determine the water supply plan for the building. Since the building has nine floors and is a high-rise building, in order to improve the reliability of the water supply, it is divided into low and high areas, and different riser connections are used, and a separation valve is provided[2]. When the inlet pipe in the low zone is damaged or faulty, or the pressure of the outer pipe network cannot meet the water supply demand, the partition valve is opened to supply water from the high zone to the low zone.

The building uses the urban water supply network as the water supply source. The preliminary estimation of

\footnotetext{
* Corresponding author: yellicheng@qq.com
}

the floor is divided into: 1 to 7 floors for one area (low area),and 8 to 9 layers for the second area (high area). The water supply is directly carried out in the low zone, and the water supply is carried out in parallel between the water pump and the water tank in the high zone. A water storage tank should be provided in front of the water pump below the building to improve the water reliability of the residents in the lower area.

\subsection{Basic water design for buildings}

The water storage equipment of the building is a high-level water tank, which has significant advantages in adjusting the amount of water and storing domestic water, stabilizing the indoor water supply pressure and storing fire water. The pressure reducing valve can automatically reduce the pressure of the water to reach the required value, and the pressure value after the valve can be adjusted within a certain range, which is an automatic regulating valve.

The average daily water consumption of the building is 800 , and the water consumption quota is $30 \mathrm{~L}$, and the maximum daily water consumption is $24 \mathrm{~m}^{3} / \mathrm{d} \cdot \mathrm{K}_{\mathrm{h}}=1.5$, $\mathrm{T}=8$, the maximum water consumption is $4.5 \mathrm{~m}^{3} / \mathrm{h}$; the highest daily average water consumption is $3 \mathrm{~m}^{3} / \mathrm{d}$.This article refer to the number of sanitary appliances arranged in the building, the number of uses, the water quota per person per day, the time of use,and the hourly coefficient of change. Set the flushing water tank type to $\mathrm{N}=0.5$ and the automatic flushing apparatus to $\mathrm{N}=0.5$, wash basin is $\mathrm{N}=0.75$. The probability of simultaneous outflow is 
calculated based on the total number of water supply equivalents of the sanitary appliance.

Finally,calculate the hydraulic power of the water supply network of the building. The steps are as follows:

(1) First determine the size of each pipe segment in the water supply network; secondly, the pipe head loss is determined to determine the water pressure demand value of the entire water supply network.

(2) The water supply method for the building is the water pump-water tank-pressure reducing valve.In addition, the head and flow of the pump and the height and volume of the high water tank need to be determined. According to the calculated results, the appropriate pump model and the model of the high water tank are selected.

(3) To determine the pipe diameter,first calculate the value of the design second flow of each pipe segment,and then select the appropriate flow rate according to the flow velocity range of different pipe diameters to calculate the pipe diameter.

(4) The pipe diameters of different sizes are also different, and the flow rate affects the rationality of the economics of the pipeline system.If the flow rate is too large, the noise will increase,which will affect the normal use and rest of the user. It will also cause serious damage to the water supply pipe and accessories,reduce the service life of the pipe, and improve maintenance and maintenance costs, causing many inconveniences. Excessive flow rates will also increase the loss of the head along the path and also damage the local head, causing the water pressure required by the system to rise. In the opposite case, if the flow rate is too small, the pipe will be wasted and the optimal design of the system will not be achieved[3].

In actual engineering,due to the large number of pipe fittings, if detailed calculations are carried out, the process will be cumbersome. Therefore, it is not necessary to calculate the loss of the local head, but the percentage of the head loss along the path is estimated. We can take $30 \%$ here and calculate that the local head loss is $2.883 \mathrm{kpa}$, and the sum of the along and local losses is $12.484 \mathrm{kpa}$.

\subsection{Building safety water design}

The living water supply system of high-rise buildings needs to ensure the normal use of domestic water safely and on the ground, so it is necessary to set up a water storage tank. The volume of the reservoir should be determined according to the actual water demand of the building, and then based on the reliability of the water supply to the pipe network. The plan adopted by the building is to use a storage tank for living water supply and fire water supply.

The safety reserve of the building is $9 \mathrm{~m}^{3}$, the fire reserve is $108 \mathrm{~m} 3$, and the volume of the storage tank is $119.88 \mathrm{~m}^{3}$. Therefore, the standard rectangular storage tank is selected with a volume of $200 \mathrm{~m}^{3}$ and a size of $7600 \mathrm{~mm} * 7600 \mathrm{~mm} * 3500 \mathrm{~mm}$. The top level of the pool is $-2.5 \mathrm{~m}$, the highest water level is $-2.8 \mathrm{~m}$, the bottom level is $-5.8 \mathrm{~m}$, the living water level is $-3.0 \mathrm{~m}$, the fire level is $-3.6 \mathrm{~m}$, and the pump suction pipe center elevation is
$5.1 \mathrm{~m}$

\section{Building drainage design}

The internal drainage system of the building should ensure that the domestic sewage can be quickly discharged under relatively stable atmospheric pressure conditions, and the harmful gases in the pipeline are also discharged at the same time, thereby ensuring a good indoor air environment. The building adopts a confluence system, that is, a combination of fecal sewage and domestic wastewater is used to discharge the sewage to the sewage treatment plant, and no need to set up a septic tank.The requirements for the layout of the drainage pipes of high-rise buildings are the shortest length, straight pipelines, which are conducive to maintenance management, ensuring the normal use of rooms or places with drainage pipes, ensuring that the pipes are not easily damaged, meeting the aesthetic needs, and reasonably controlling economic expenditures[4].

\subsection{Laying and installation of drainage pipes}

The laying and installation of the drainage pipe needs to meet the following requirements:

1) In the high-rise buildings, all the drainage pipes are concealed except for the pipes placed in the basement and equipment floors. The drainage riser is internally laid with concealed equipment, that is, in the pipe tip, the pipe groove and the pipe, the horizontal branch pipe is embedded in the pipe tip, or the ceiling flat decoration space is used for treatment.

2) The pipe is suitable for being arranged on one side, and the other side is used as an access passage, and the diameter at the narrowest point of the passage is not less than $450 \mathrm{~mm}$.

3) The distance between the drain pipe and the outer wall of other pipes should be greater than $150 \mathrm{~mm}$, especially the distance between the drainage pipe and the water supply pipe, and the expansion can be carried out when conditions permit. The drain riser and the drain vent should be kept at an appropriate distance for easy connection with the venting pipe (if the spacing is insufficient, the $\mathrm{H}$ pipe can be used).

\subsection{Drainage design second flow}

Since the determination of the pipe diameter of each pipe section in the building is determined by the design flow of the pipe, the secondary flow of the drainage design must conform to the drainage law[5]. The internal drainage flow is related to the drainage characteristics of the appliance and the number of appliances. There may be shortcomings such as large instantaneous flow, short time, long interval, and uneven drainage.In order to ensure that the maximum displacement can be smoothly discharged in the worst case, the drainage design flow rate of the pipe section should be set to the instantaneous maximum displacement. 


\section{Fire water supply system}

The fire hydrant water supply system is generally composed of a water gun, a water hose, a fire hydrant, a fire hose, a fire pool, a high water tank, a water pump adapter, and a booster water pump.According to the design indicators of the building, the water heater is supplied by means of setting the water tank[6].The position of the fire hydrant should ensure that the water column of the water gun with 2 fire hydrants in any part of the same layer can reach at the same time, so four should be arranged on each aisle, the spacing should be less than or equal to $17 \mathrm{~m}$.In addition, the front room of the fire elevator should also be placed one.

The pressure required at the water gun nozzle of the fire hydrant is 16.9 , the water resistance loss value is $0.93 \mathrm{~m}$, the water pressure required for the fire hydrant opening is $198.3 \mathrm{kpa}$, the fire water tank volume is $7.2 \mathrm{~m}^{3}$, and the size is $2.0 \mathrm{~m} * 2.0 \mathrm{~m} * 3 \mathrm{~m}$. The effective water depth is $1.8 \mathrm{~m}$. The minimum water level elevation of the fire water tank is set to $33.5 \mathrm{~m}$, and the most unfavorable point fire hydrant elevation is $26.5 \mathrm{~m}$. Then the most unfavorable point is the static water pressure value of the fire hydrant opening is $33.5-26.5=7 \mathrm{mH} 2 \mathrm{O}=70 \mathrm{kpa}$. The lift of the fire pump is $539 \mathrm{kpa}$.According to the above calculation data, two sets of fire pump 100DL-3 type and one set are used as spare.

\section{Building rainwater drainage system}

During heavy rain, the water in the house is quickly and smoothly discharged to the outside through the rainwater drainage system. Otherwise, the phenomenon of water on the roof will affect the normal life of people.The classification of building roof rainwater drainage systems is related to the setting of pipelines, pressure in pipes, water flow conditions and roof drainage[7].

The building uses a gutter drainage system that will not cause leakage or water in the roof due to poor construction and will maximize material savings. The gutter drainage system mainly consists of three aspects: gutter, rainwater bucket and drainage riser. The gutter allows the discharge flow rate of $164.3 \mathrm{~L} / \mathrm{s}$ to be greater than the rainwater design flow rate of $3.71 \mathrm{~L} / \mathrm{s}$. According to the gravity semi-pressure flow design, the $100 \mathrm{~mm} 87$ type rainwater bucket is used, and the maximum discharge flow is $12 \mathrm{~L} / \mathrm{s}$. According to the rainwater flow rate of each riser of $3.71 \mathrm{~L} / \mathrm{s}$, a pipe with a size of $75 \mathrm{~mm}$ can be used. The single-bucket system rainwater downpipe diameter is not less than the rain bucket diameter, so we can use a $100 \mathrm{~mm}$ riser.

\section{Conclusion}

The technology of water supply and drainage engineering for high-rise buildings has become more and more perfect, and problems that may arise during the construction process have also been dealt with. Some attention will also be paid to some details, but it is necessary to strengthen the attention and ensure the correctness of the construction. The data and solutions of this design are targeted and not applicable to all nine-story buildings, only for reference.

\section{Foundation items:}

1. Development and Application of Intelligent Security Early Warning System for Visitors in Smart Scenic Areas and Time-Space Virtual Reconstruction Technology Item Number: 20170220

2. Research on Intelligent Indoor Positioning

Method Based on WIFI and Its Application

Item Number: 2018-B-02

\section{References}

1. Z. Z. Wang, Y. F. Gao. Building water supply \& sewerage engineering(Fifth Edition). China Architecture \& Building Press, 05(2007).

2. L. Xu. Control of fire water supply to high-rise residential buildings. Sichuan Building Materials, 03(2010).

3. X. D. Han. Optimal design of water supply and drainage in high rise buildings. Scienceand Technology, 34(2015).

4. H. W. Cheng, D. M. Liu. Study on municipal direct and secondary pressurized water supply methods for building water supply system. Water \& Wastewater Engineering, 40(2014).

5. X. Q. Gao. Design Analysis of Water Supply and Drainage in Modern Residential Buildings. New Technology \& New Products of China, 07(2012).

6. S. Z. Zhu. Talking about some views on the design of building water supply and drainage. Urban Construction Theory Research, 06(2014).

7. M. S. Liu, R. Z. Yang. Calculation of the selection and capacity of high-pressure non-negative pressure water supply equipment. Journal of Chengde Petroleum College, 05(2015). 